\title{
Goethe y Bürger: el comienzo del Romanticismo negro
}

\author{
Notas sobre Los muertos cabalgan deprisa: Leonora de G.A. Bürger y \\ La novia de Corinto de J.W. Goethe, en edición de H.Cortés, La Oficina \\ de Arte y Ediciones, Madrid, 2015.
}

\author{
Ana CARrasco Conde
}

Recibido: 12/11/2015

Leonora y La novia de Corinto, Gottfried August Bürger y Johann Wolfgang von Goethe. Ni hay castillos ni paisajes agrestes en los Cárpatos, tampoco montañas y picos nevados, menos aún construcciones inexpugnables, pero sí lápidas y muerte. Hay también dos jóvenes que ansiaban desposarse: la primera, la protagonista del poema de Bürger, reniega de un Dios que no puede devolverle al prometido que cree muerto en la guerra: “¡Ay, madre mía! ¿Pero, qué es la gloria, / ay madre, qué es el infierno? / ¡Con él y solo con él hay gloria, / solo sin Wilhelm infierno! [...] Así desespera su conciencia, así de rabia se anega su alma; contra la divina providencia" (p. 13); la segunda, una joven doncella que en mitad de la noche se introduce en la alcoba del que debiera haber sido su esposo. No debiera estar allí... por ser conducta inapropiada y ipor estar muerta! Ella reniega también del dios único y la nueva fe y así se lo reprocha a su madre que, asustada, la sorprende entre las sábanas: "Este joven ya me fue prometido, / cuando aquí Venus su templo aún tenía, / esa promesa no la habéis cumplido, / porque un falso voto a fe ajena os guía" (p. 39). Hay también, por lo dicho, dos víctimas de lo inexplicable, de lo antinatural, de aquello que no respeta el límite entre la vida y la muerte. La primera es desposada por un muerto y tal será su castigo: tener como tálamo nupcial, seis clavos en dos tablillas y toda una comitiva fúnebre nupcial (p. 17), la segunda será una muerta que arrastra a su vez a la sombra de la muerte a quien con ella yazca en el lecho: "Del sepulcro me he visto yo expulsada, / para buscar el bien que me robaste: / ser de mi perdido esposo aún amada, / la sangre de su corazón chuparle. / Cuando acabe con él, / buscaré otro doncel, / mi rabia en otros sabrá desfogarse" (p. 39). La acción tampoco se sitúa en la Edad Media, en la guerra contra los turcos, por poner el ejemplo de Drakul, sino en Prusia tras la Guerra de los Siete Años, en torno a 1763, -caso de Leonora- y en Grecia, Corinto en una época ya de cristianismo -caso La novia de Corinto. No por casualidad, por cierto, esta ciudad es uno de los puntos estratégicos de las conversiones logradas por San Pablo.

Estas dos baladas, que conforman la edición de Los muertos cabalgan deprisa, tienen varias cosas en común además de lo ya dicho, como su relación con el prerro- 
manticismo y el Romanticismo: ambos fueron publicados en una revista del mismo nombre, "Almanaque de las musas", aunque de diferente origen: la primera, se refiere a la revista editada en Gotinga, la misma que por estas fechas hacía alarde de unas de las mejores universidades de la época y una de las primeras en oponerse a Kant (y Bürger sería uno de los que incentivarían el estudio de la obra kantiana en Gotinga); y la segunda revista fue auspiciada nada más y nada menos que por Schiller en 1798, y que se relaciona con el editor Cotta en Tubinga. El primero de los poemas apareció en 1774 y el segundo en 1798, aunque fue compuesto por la pluma del siempre genial Goethe en 1797. Por lo tanto, éste es nuestro contexto: Alemania a finales del siglo XVIII. Nos situamos en una época muy fecunda para el pensamiento: son los años inicialmente del Sturm und Drang, que dará paso al surgimiento del primer Romanticismo, del final del racionalismo ilustrado y de la filosofía kantiana, de la aparición, esplendor y caída del fichteanismo, de los primeros pasos de Hölderlin, Schelling y Hegel.

Hay más puntos en común. Son, por ejemplo, como encontramos mencionado en el subtítulo del libro a modo de presentación -y explicado detalladamente en el estudio final que los acompaña- el origen de lo que, andando el tiempo, será un género en sí mismo: el de la literatura gótica y de vampiros y, un poco más adelante, y con todas las matizaciones que implica la introducción de una temática casi ilimitada, el de las novelas de terror. Señalo aquí y con énfasis el concepto "novela", del francés roman, que dará origen al vocablo "romanticismo". Como antecedentes de toda una corriente de amplio calado en nuestra cultura popular, muchos de los elementos contenidos en ellos aparecen, de un modo u otro, y con más o con menos modificaciones en productos de consumo masivo como el conocido Drácula de Stoker, interpretado en el cine por Bela Lugosi, Christopher Lee o Gary Oldman, el más baudelaireriano de todos los Condes transilvanos, en la saga Crepúsculo basada en las novelas de Stephenie Meyer o en la exitosa serie de televisión, True Blood. En todos ellos el tema central es la muerte o, mejor dicho, aquel que no estando vivo, tampoco está muerto: su cuerpo mismo, aunque frío y pálido, es el que fue. No se trata tanto de un fantasma que vuelve, que retorna de la muerte, como de un muerto que no estando vivo insiste en su existencia, de ahí por cierto, una de las claves de ambos poemas: el goce de los placeres (eróticos) de la carne e, incluso, como en el caso de La novia de Corinto la ingesta de vino que es, muy simbólicamente, comparado con la sangre. "Yo no bebo... vino" afirma Bela Lugosi interpretando a Drácula, aunque no hace ascos, como bien sabemos, a beber sangre fresca recién vertida en una copa (o un cáliz). Dejo aquí un hilo para recoger después. De la misma película de Coppola menciona Helena Cortés un fragmento en el que los versos de Bürger, que dan título a esta edición, resuenan en toda su fuerza: Jonathan Harker increpa al cochero que debía recogerle para llevarle al castillo cuando llega antes de lo previsto. Tras su respuesta -"Mis caballos son rápidos"- uno de los compañeros de viaje de musita "porque los muertos cabalgan deprisa". Por cierto que desde entonces es costumbre 
también creer que los vampiros se desplazan a una velocidad tal que ningún ojo humano puede captarlos en movimiento. Se inicia así, en torno a la muerte y en estos años, un tipo de literatura que recibirá el calificativo de "Romanticismo negro" que ha de ser entendido como una modulación de los Romanticismos de la época.

\section{Grecia y Alemania}

El Romanticismo había hecho de la muerte también tema, pero más como fin de un trayecto o límite último en el que sólo cabía abandonarse para diluirse sin remedio. La búsqueda de la belleza, de una Naturaleza que nos excede, tiene en este momento varias formas, pero todas ellas dan cuenta de algo inasimilable para la razón, que es extraño y, al mismo tiempo, causa asombro. Quedémonos con esta idea del asombro. No en vano, como señala Helena Cortés "Cabría preguntarse si, como todo el Romanticismo en general, aparece en las postrimerías de este siglo para compensar los excesos del Racionalismo o tal vez porque, de un modo u otro, también la propia razón produce monstruos” (p. 45). Pero ¿cuáles son, pues esos monstruos? ¿Qué relación mantienen el Romanticismo y el Romanticismo negro?

En primer lugar habría que decir que la Naturaleza no sólo nos excede, como decíamos antes, sino que de ella surgen la amenaza y el peligro: a través de sombras en la noche que nos acechan, pero también a través de nosotros mismos que albergamos, como bien empezaron a ver los círculos de los Naturphilosophen, una naturaleza -desconocida para nosotros mismos- en nuestro interior. Son los tiempos de las corrientes espiritistas de tanto predicamento en el XIX, del surgimiento del inconsciente y del "magnetismo animal" que afirma que en el sueño se desataban las fuerzas naturales más elementales y originarias porque se deja abierta una entrada que vincula la parte visible - diurna- del todo con la cara "nocturna" de toda existencia. Obsérvese que la acción de ambos poemas, el de Leonora y La novia de Corinto se da a media noche, en el límite o en la franja que separa un día de otro.

En segundo lugar si el Romanticismo dentro de su programa recuperaba elementos del medioevo y de las leyendas populares, en respuesta al llamamiento de Herder para crear una literatura popular alemana -que es, por cierto, lo que haría Bürger en su Leonora al emplear la lengua de Lutero mas que el modelo lingüístico del humanismo grecolatino- sin perder nunca sin embargo la admiración por lo griego y, además, se había girado en muchas ocasiones hacia la fe cristiana (Recuérdese Cristiandad o Europa de Novalis, de 1799), el Romanticismo negro presenta una curiosa combinación de estos elementos: una lucha contra la Ilustración, una recuperación de lo medieval, pero también la influencia de una de sus grandes fuentes, diluida poco a poco con el tiempo hasta su desaparición: si existe una influencia "diurna" de Grecia en la Alemania del XVIII y XIX, también existe dentro del ámbito del Romanticismo negro la influencia de otra Grecia. La Grecia negra. No una Grecia de océanos azules y vuelo de grullas, sino una Grecia desconocida, de agua y cielos 
negros, de muerte, de apariciones espectrales y de vampiros. Una Grecia que no sólo aparece en referencias en la contextualización de la historia, como la de Goethe, que se desarrolla en Corinto, sino conlleva la asimilación de toda una tradición que se emparenta con los paradoxógrafos griegos, aquellos mismos que, ya en el siglo VI a.C. en Jonia se empleaban afanosamente en recoger "casos sorprendentes" de un mundo desconocido que se estaba descubriendo. Recojo en este punto una de las puertas abiertas por Helena en su estudio: a la hora de buscar antecedentes en las historias de vampiros y de la novela gótica, siempre puede retrocederse un poco más (p. 42). Si hay un conocido cuadro de Overbeck titulado "Italia y Germania" (1828) podríamos hablar aquí de otra alegoría no menos poderosa: la de "Grecia y Germania".

\section{La otra Grecia}

La propia Helena Cortés señala el texto clásico, de unos de estos paradoxógrafios griegos, en que se basó Goethe en La novia de Corinto: las noticias recogidas por Flegón de Trales, liberto del emperador Adriano, en Sobre los hechos maravillosos (s. II). El texto de Flegón se encuadra dentro de una tradición, a la que pertenecen Calímaco o Apolonio, que trataba de recoger todo aquello que se quedara fuera de los parámetros de lo normal: cosas maravillosas (De Rebus Mirabilis). El origen, como se indicaba antes, es Jonia, cuando tras tantos viajes y confluencia de realidades, se dan cuenta de "rarezas y maravillas", que, pese a todo, deben ser catalogadas y asimiladas dentro de una red racional de comprensión del mundo y que, como en el caso de las narraciones del Romanticismo (con énfasis en el negro), acabó desembocando en una serie de narraciones para consumo masivo cuyo enfoque dramatizante trataban de implicar a fondo las emociones del lector. De hecho, maravillas y hechos fantásticos, que abarcan los mismos fenómenos pero desde diferentes perspectivas, es lo que aparece en los textos románticos: como el clásico de Tieck "El tratamiento shakespeano de lo maravilloso" (Shakspeare's Behandlung des Wunderbaren) (1793) o, en música, la "Sinfonía fantástica" de Berlioz, -cuyo título completo es Episodio de la vida de un artista, sinfonía fantástica en cinco partes- (1830).

El mundo clásico, aunque suele olvidarse, es rico en estas narraciones fantásticas - pese a que no son pocas las veces que se ha considerado que el origen de las historias de fantasmas tiene su acta de nacimiento en Inglaterra con El castillo de Otranto de Horace Walpole. Pero ya encontramos desde historias de fantasmas en Plinio el Joven, con un fantasma que busca una adecuada sepultura, en Plauto con su Mosteralia, e incluso en Cicerón que dará cuenta en su De divinatione de la historia de Simónides a quien, tras enterrar correctamente un cadáver, se le apareció su espectro para darle las gracias; también habrá menciones a los hombres lobo y a las brujas, como en El Satiricón de Petronio; y finalmente, por el tema que nos ocupa hoy aquí, encontramos antecedentes de los vampiros, como en Flegón de Trales, un historiador interesado en anécdotas e historias inexplicables. Él es autor de la na- 
rración sobre la novia cadáver, tan del gusto de Tim Burton, y que es la historia que influye, según se afirma, en el poema de Goethe. Muchos serán los parecidos, como veremos. Allí se narra la historia de Macates, un joven hospedado en un hostal en las cercanías de Anfípolis -no en Corinto, cuya elección por parte de Goethe no es casual como veíamos- , una población cerca de Macedonia y por tanto no muy lejos de la famosa Transilvania. Macates recibe al caer el sol la visita en carne y hueso de Filonea, fallecida hace poco tras contraer contra su voluntad matrimonio, pero de cuya muerte Macates nada sabe. Con ella comparte lecho y sábanas durante tres días, gracias a la ayuda de los dioses del infierno. Cuando ante los ruidos nocturnos y por conversaciones con el joven los padres de Filonea tienen noticia de estas visitas, una noche deciden esperarla. Transcribo un pequeño pasaje: "Demóstrato y Caritó la vieron y se quedaron mudos y estupefactos en un primer momento a causa de lo asombroso de la visión y después prorrumpieron en grandes gritos y se precipitaron sobre su hija. Entonces Filonea les dirigió estas palabras: "Madre y padre, cuán injustamente os mostráis recelosos de que con el huésped haya estado durante tres días sin ser motivo de aflicción en cada paterna. Vosotros os lamentáis desde el principio a causa de vuestra excesiva curiosidad; yo en cambio regresaré de nuevo al lugar establecido; pues no llegué hasta aquí sin la voluntad divina". Cuando pronunció estas palabras al instante mismo se convirtió en cadáver, y extendió su cuerpo visible sobre el lecho". La voz corre por Anfípolis y, para terror de sus habitantes se comprueba que la tumba está vacía, pero también para espanto de Macate que muere tras tan terrible experiencia. Es, por tanto, una no-muerta (Nosferatu). Es cierto que Filonea no es una vampiresa como tal -no se alimenta de su sangre- pero influye en lo que, con Goethe, se consagrará como tal. Aparecen varios de los elementos que acabarán confluyendo en los vampiros: aparición durante la noche, una corporalidad, aunque fría y pálida, que trata de calentar el seducido, vestidos y velos blancos (partes de un sudario), gusto por los placeres carnales y una relación con divinidades paganas.

La novia de Corinto presenta, en la bisagra entre la nostalgia de Grecia y el triunfo del cristianismo, una reflexión entre lo pagano y lo cristiano: la sangre de Cristo -vino- que es bebida en el cáliz por los hombres para su salvación, es bebida ahora como sangre misma por el vampiro para provocar la condenación. De ahí el origen del término vampiro que procede de las lenguas eslavas y que significa tanto "beber" o "chupar"como "ser volador" y "lobo" (p. 58). En este caso, el Drácula de Bram Stoker, incide en este poder de la transformación, pero también en la relación entre la sangre que bebe el vampiro y la sangre de Cristo: Drácula ha de buscar el perdón de Dios en el mismo lugar -piénsese en la película de Coppola- en el que clavó su espada, ante la muerte de su amada: la cruz. De ella mana sin cesar sangre que el conde recoge con un cáliz y bebe. Por cierto que, como el Lenore, la condenación se ha producido por el rechazo al dios cristiano ante el fallecimiento de la persona amada. 


\section{La otra Grecia que recorre Europa en el XIX}

Esta aparición de Grecia que recorre Europa -por parafrasear a Marx- antes de fijarse en los Cárpatos por influencia de los casos reales de vampirismo que asolan el este de Europa entre 1718 y 1732 (y que aparecen, por ejemplo, en la inmejorable $E l$ baile de los vampiros de Roman Polanski, 1967), tiene también ya en pleno Romanticismo inglés su eco. Es el caso de "El vampiro" escrito por Polidori tras la famosa noche del 17 de junio de 1816 (que vio nacer a la gran obra de la literatura de terror, Frankenstein de Mary Shelley). El vampiro descrito por Polidori, con muchos rasgos ya bien reconocibles en el famoso conde, se mueve entre la alta sociedad y tiene sus modos, sus maneras, pero un halo de misterio que seduce a quien le rodea. Es un dandy, un galán, un seductor: "En aquel tiempo apareció, en medio de las frivolidades invernales de Londres, en las numerosas reuniones a las que la moda obliga en esta época, un lord más que notable más por su singularidad que por su alcurnia"120. El lord, de nombre Ruthwen, seduce a un joven huérfano de gran fortuna, lord Audrey y ambos parten de viaje por Europa. Las ciudades que recorren son escenario de la depravación y corrupción que lord Ruthwen esparce a su paso. Al llegar a Italia, lord Audrey saldrá de su hechizo: escarmentado por las perniciosas costumbres del lord le abandona y, dirige sus pasos en solitario...hacia Grecia, para hospedarse en una casa en la que vive la hija de los mesoneros, como en la historia de Flegón, de la que caerá enamorado. Pero ella no está todavía muerta. Allí escucha las primeras historias de vampiros según las cuales éstos prolongan su existencia a través de la sangre de sus víctimas. Su amada le insiste en la existencia de los vampiros, en los que él se niega a creer, hasta que ella es víctima de su mordedura fatal: "en su cuello y en su seno se veían manchas de sangre y su garganta mostraba las huellas de los dientes crueles que habían abierto sus venas" ${ }^{\prime 21}$. El devenir de la historia hará ver que es lord Ruthwen, el encantador galán, el vampiro y lord Audrey acabará perdiendo la cordura. De los paisajes griegos de Corinto, una de las grandes ciudades del mundo antiguo, pasamos así al paisaje agreste de los Balcanes, por mediación de Stoker, que condensa las supersticiones de la Europa del mundo moderno. Y tras éstos otros tiempos arrastrando viejas tradiciones en nuevos parajes cerca de las centros urbanos más importantes del mundo contemporáneo: desde los campos de Louisiana, Nueva Orleans, uno de los lugares más importantes de las colonias europeas francesas en el nuevo mundo, como en True Blood o en Lestat el vampiro, de Anne Rice, a los bosques salvajes de Forks, Washington, descritos en Crepúsculo.

\footnotetext{
${ }^{120}$ Polidori: "El vampiro". En Siete cuentos de terror, Alianza, Madrid, 2202, p. 53.

${ }^{121}$ Ibid, p. 66.
} 


\section{El asombro y la muerte}

Llegados a este punto, con estas reflexiones en torno a Leonora de Bürger y La novia de Corinto de Goethe, que han dejado de manifiesto la recepción de algunos de los elementos de la Grecia negra en los orígenes de la literatura de vampiros, me gustaría plantear una historia del pensamiento alternativa. Grecia y Alemania, por distintos motivos y en diferentes épocas, ha constituido momentos de esplendor en la historia del pensamiento: Grecia, con las colonias jonias del siglo VI a.C. y su época de ilustración ateniense del siglo V, y Alemania, con su época de ilustración, el criticismo y con el periodo del idealismo alemán que suponen, como bien se sabe, una revolución en el pensamiento. En ambos casos, el griego y el alemán, se ha tratado de dar cuenta de aquello que excede a la razón: a través de los "hechos extraordinarios" de los paradoxógrafos, o través del desarrollo de un sistema racional que todo lo englobe -todo lo real es racional dirá Hegel- al mismo tiempo que surgen nuevas teorías médicas como el mesmerismo, el hipnotismo, el inconsciente, con unas sombras "románticas" que proceden de la razón misma o la exceden... Ahora bien ¿y si el pensamiento no surgiera de la maravilla o del asombro (thaumazein) como sostiene Aristóteles en la Metafisica (Libro I, vv. 12-16), sino del espanto, de aquello que literalmente nos descoloca y nos hace tambalear? Por cierto, que el término griego, "thauma", significa sorprenderse ante algo, no necesariamente de forma positiva. Asombrarnos sería así incitar al movimiento que nos saca de la sombra.

Si en la otra Grecia el motivo de reflexión eran los mirabilia, en el Romanticismo sería también lo que causa sorpresa, das Wunder y la sorpresa nos causa también horror, espanto, ruptura del horizonte de significatividad y necesidad de control sobre aquello que nos perturba asimilándolo, aunque sea, como parte de una ficción que la razón pueda integrar en su discurso. Quizá entonces lo que impulsa al pensamiento sea justamente generar una red racional, una base segura, que nos proteja ante los espantos del mundo y, sobre todo, ante el asombro del milagro de la vida frente a la muerte - “¿Por qué hay algo y no más bien nada?" se preguntará Leibniz-. Tiembla Leonora en el poema de Bürger, al oscilar entre la vida y la muerte (p. 23), y su difunto prometido se interesa por si es víctima del susto o del espanto: “¿Te asustas niña?... ¡la luna brilla! ¿yuuuuh los muertos cabalgan deprisa! ¿Te dan espanto los muertos?”. Tiemblan también en la casa de Corinto, como temblaban en la casa de huéspedes de Anfipolis, ante la muerte o, mejor dicho, ante lo que cruza el umbral que separa la vida de la muerte. Quizá Max Scheler tuviera razón y si la religión nace del deseo de salvarse de la muerte, la ciencia nace del deseo de querer dominarla o, en su defecto, de querer dominar a la naturaleza... A algo parecido apunta Helena Cortés cuando afirma: "los relatos de terror y las fantasías sobrenaturales son tan antiguos como la sociedad humana" por eso -añade- el miedo a la muerte sería, desde el punto de vista psicológico, la raíz más profunda (p. 52), y quizá por eso, hoy, como ayer, sigamos intrigados por imaginar, en la ficción, qué es lo que hay más allá de la cara diurna de la existencia. 